\title{
High competing risks minimize real-world utility of adjuvant targeted therapy in renal cell carcinoma: a population-based analysis
}

\author{
Thenappan Chandrasekar ${ }^{1}$, Zachary Klaassen ${ }^{1}$, Hanan Goldberg ${ }^{1}$, Rashid K. Sayyid ${ }^{1}$, \\ Girish S. Kulkarni ${ }^{1}$ and Neil E. Fleshner ${ }^{1}$ \\ ${ }^{1}$ Department of Surgical Oncology, Division of Urology, University Health Network, University of Toronto, Ontario, Canada \\ Correspondence to: Thenappan Chandrasekar, email: thenappan.chandrasekar@gmail.com \\ Keywords: carcinoma, renal cell; neoplasm metastasis; drug therapy; survival; mortality \\ Received: August 29, $2017 \quad$ Accepted: February 26, $2018 \quad$ Published: March 30, 2018 \\ Copyright: Chandrasekar et al. This is an open-access article distributed under the terms of the Creative Commons Attribution \\ License 3.0 (CC BY 3.0), which permits unrestricted use, distribution, and reproduction in any medium, provided the original author \\ and source are credited.
}

\section{ABSTRACT}

Objective: To utilize a population-based approach to address the role of adjuvant TT in the management of RCC.

Methods: Patients with RCC (2006-2013) in the SEER database were stratified by metastatic disease at the time of diagnosis (CMO/CM1). CM0 patients following surgical excision were stratified into low and high-risk (ASSURE and S-TRAC criteria). Multivariable analyses performed to identify predictors of TT receipt; Fine and Gray competing risks analyses used to identify predictors of cancer-specific mortality (CSM). Subset analyses included patients with clear cell histology and high-risk cM0. Survival analyses were used to evaluate overall survival (OS) and cancer-specific survival (CSS) for all cohorts, stratified on TT receipt.

Results: 79,926 patients included (71,682 cM0, 8,244 cM1); median follow-up for the entire cohort was $\mathbf{4 0 . 1}$ months. Of 31,453 patients with histologic grade data, 18,328 and 13,125 were low- and high-risk cMO, respectively. TT utilization in CM1 patients peaked at $50.6 \%$ and was associated with reduced CSM (HR $0.73, \mathrm{p}<0.01$ ). In contrast, TT utilization (presumed salvage therapy) never exceeded $2.2 \%$ in the entire CMO cohort and $3.5 \%$ in the high-risk CMO cohort. On competing risks analysis, TT receipt was associated with increased CSM in all cohorts.

Conclusion: When compared to the CM1 patients, TT receipt in cMO patients does not provide any cancer-specific survival benefit, even in the small percentage of patients that eventually progress to metastatic disease. Competing risks mortality further limit any potential benefit in this population. Based on current evidence, adjuvant TT cannot be recommended for RCC patients.

\section{INTRODUCTION}

Renal cell carcinoma ( $\mathrm{RCC}$ ) has traditionally been surgically managed. Extirpative surgery, either radical nephrectomy $(\mathrm{RN})$ or partial nephrectomy $(\mathrm{PNx})$, remains the standard of care for localized disease $[1,2]$. Radiation therapy and systemic therapy have not been proven to be effective for the management of localized disease.

Targeted therapies (TT), including tyrosine kinase inhibitors (TKIs) and mTOR inhibitors, were first introduced in 2006 [3-5]. Since then, they have become a cornerstone of RCC therapy, specifically for metastatic RCC [1]. Utilized in patients with de novo metastatic RCC or patients with metastatic progression following primary surgical management, they have been demonstrated to extend progression-free survival by 3-8 months in patients with clear-cell histology $[1,2,6,7]$. Their introduction has even called into question the oncologic value of cytoreductive nephrectomy, which was first established in the cytokine era [8-11].

While the efficacy of targeted therapies is well established for metastatic RCC, its role as an adjuvant 
therapy is less clear. Two randomized controlled trials (RCTs) demonstrated conflicting cancer-specific survival outcomes with sunitinib and sorafenib in the adjuvant setting for high-risk localized RCC [12-15]. In ASSURE, there was no significant difference in disease-free survival (DFS) between high-risk patients treated with sunitinib, sorafenib or placebo, while in S-TRAC, sunitinib-treated patients had a 1.2 year improved DFS. Given these conflicting results, we aim to examine the utilization of TT in the targeted-therapy era. In doing so, we aim to identify predictors of TT receipt and cancer-specific survival (CSS), particularly in patients with non-metastatic localized RCC treated with definitive surgery, to further examine the role for adjuvant therapy in these high-risk patients.

\section{RESULTS}

\section{Demographics}

Table 1 details the demographics of the entire cohort $(\mathrm{N}=79,926)$, stratified by $\mathrm{cM} 0(\mathrm{~N}=71,682)$ or cM1 $(\mathrm{N}=8,244)$ at the time of diagnosis. Patients with cM1 disease were more likely to be older, male, and underinsured, while also presenting with higher $\mathrm{cT}$ and $\mathrm{cN}$ stage. Most $\mathrm{cM} 0$ patients underwent primary surgical intervention, while only $45.9 \%$ of $\mathrm{cM} 1$ patients had surgery. Median follow-up for the entire cohort was 40.1 months ( \pm 27.7 months).

For the $31,453 \mathrm{cM} 0$ patients who underwent primary surgical treatment and had FG available, further stratification into high and low-risk cM0 RCC was completed, as described previously (Supplementary Table 1B). While both groups had similar rates of surgical intervention, patients with high-risk cM0 disease predominantly underwent $\mathrm{RN}$, while those with low-risk disease were equally likely to receive RN or PNx. Median follow-up was similar between the groups.

\section{De novo metastatic (cM1) RCC and targeted therapy}

From 2006 to 2013, the proportion of eligible patients receiving targeted therapy steadily increased (Figure 1).

Table 2A highlights the predictors of TT receipt in this population. Higher cT-stage and presence of nodal disease at diagnosis increased TT utilization, while surgical intervention ( $\mathrm{RN}$ or PNx) decreased it. Older patients, patients in the lowest SES quartile, uninsured or Medicaid patients, and single or widowed patients were less likely to receive TT. Histology of the primary tumor did not impact TT receipt in this population. On competing risks analysis assessing predictors of CSM (Supplementary Table 2B), the use of TT was associated with reduced CSM. Higher cT-stage, $\mathrm{cN}+$ disease, and papillary and sarcomatoid histology were the strongest predictors of increased CSM, but older age, being widowed, and treatment in the Midwestern US were also associated with increased CSM. Surgical intervention drastically reduced CSM. In a subset analysis of patients with only clear cell histology (Supplementary Table 2C), the use of TT and surgical intervention were still associated with reduced CSM. In a subset analysis of $\mathrm{cM} 1$ patients who received TT (not shown), surgical intervention with RN or PNx was associated with reduced CSM (HR 0.42 and 0.47 , respectively; $\mathrm{p}<0.01)$. Figure $2 \mathrm{~A}$ depicts the CSS and OS of patients with $\mathrm{cM} 1$ disease, with the majority of events occurring within the first 20 months regardless of treatment. In untreated patients, the 5-year CSS and OS was $18 \%$ and $14 \%$, respectively; in treated patients, the 5 -year CSS and OS were $13 \%$ and $11 \%$, respectively.

\section{Non-metastatic (cM0) RCC and targeted therapy}

As TTs have not yet been approved in the adjuvant setting, TT utilization in patients with non-metastatic cM0 RCC are presumed to represent salvage therapy for recurrent disease. Between 2006 and 2013, 1.6-2.2\% of all $\mathrm{cM} 0$ patients received targeted therapy annually, while in the high-risk cM0 subset, 2.5-3.5\% of patients received targeted therapy (Figure 1).

Amongst all cM0 patients, higher cT-stage and presence of nodal disease were the strongest predictors of TT receipt (Table 3A). Surgically untreated patients were more likely to receive TT than patients who underwent RN or PNx. While patients with sarcomatoid histology were more likely to receive TT compared to patients with clear cell histology, patients with chromophobe RCC were less likely. Similar to the cM1 cohort, older patients, patients in the lowest SES quartile and single or divorced patients were less likely to receive TT. Hispanic patients were also less likely to receive TT than non-Hispanic whites. In the high-risk cM0 subset, older age and disease factors drove TT receipt (Supplementary Table 3B).

Amongst the entire cM0 cohort, higher cT-stage, $\mathrm{cN}+$ disease and sarcomatoid histology were most predictive of increased CSM (Table 4A). While surgical intervention was still associated with reduced CSM, TT receipt was associated with increased CSM. Older age, male sex, uninsured or Medicaid coverage, treatment in the Southeast, and marital status (divorced/separated or widowed) were also associated with increased CSM. On subset analysis of high-risk cM0 patients (Supplementary Table 4B), TT receipt was associated with increased CSM. Amongst the high-risk cM0 patients with only clear cell histology, TT receipt was still associated with increased CSM (Supplementary Table 4C).

Figure $2 \mathrm{~B}$ and $2 \mathrm{C}$ depict the CSS and OS of all patients with cM0 disease and the high-risk cM0 subset, respectively. Amongst the entire cM0 cohort, patients that never received targeted therapy had a $91 \%$ 5-year 
Table 1: Patient demographics, stratified by cM status

\begin{tabular}{|c|c|c|c|}
\hline & cM0 & cM1 & p-value \\
\hline Total Number, $\mathbf{N}$ & 71682 & 8244 & \\
\hline Age at Diagnosis, Mean (SD) & $61.83(13.04)$ & $64.31(12.30)$ & $<0.001$ \\
\hline Sex, Male (\%) & $45211(63.1)$ & $5619(68.2)$ & $<0.001$ \\
\hline \multicolumn{4}{|l|}{ Region (\%) } \\
\hline Southeast & $12764(17.8)$ & $1590(19.3)$ & \multirow{4}{*}{$<0.001$} \\
\hline Midwest & $12656(17.7)$ & $1454(17.6)$ & \\
\hline West & $34995(48.8)$ & $4177(50.7)$ & \\
\hline Northeast & $11267(15.7)$ & $1023(12.4)$ & \\
\hline \multicolumn{4}{|l|}{ Insurance $(\%)$} \\
\hline Medicaid & $6402(10.2)$ & $990(13.6)$ & \multirow{3}{*}{$<0.001$} \\
\hline Uninsured & $1905(3.0)$ & $323(4.4)$ & \\
\hline Insured & $54519(86.8)$ & $5962(82.0)$ & \\
\hline \multicolumn{4}{|l|}{ Marital Status (\%) } \\
\hline Single & $10280(15.1)$ & $1262(15.8)$ & \multirow{4}{*}{$<0.001$} \\
\hline Divorced/Separated & $7183(10.6)$ & $914(11.4)$ & \\
\hline Widowed & $6754(9.9)$ & $984(12.3)$ & \\
\hline Married & $43796(64.4)$ & $4834(60.5)$ & \\
\hline \multicolumn{4}{|l|}{ Race $(\%)$} \\
\hline Hispanic & $9418(13.1)$ & $1141(13.8)$ & \multirow{5}{*}{$<0.001$} \\
\hline American Indian/Alaskan & $591(0.8)$ & $92(1.1)$ & \\
\hline Asian or Pacific Islander & $3395(4.7)$ & $449(5.4)$ & \\
\hline Black & $8315(11.6)$ & $797(9.7)$ & \\
\hline White & $49575(69.2)$ & $5754(69.8)$ & \\
\hline \multicolumn{4}{|l|}{ Socioeconomic Status (\%) } \\
\hline $1=$ Highest quartile & $13711(19.1)$ & $1484(18.0)$ & \multirow{4}{*}{$<0.001$} \\
\hline 2 & $15617(21.8)$ & $1660(20.1)$ & \\
\hline 3 & $19208(26.8)$ & $2339(28.4)$ & \\
\hline 4 = Lowest quartile & $23146(32.3)$ & $2761(33.5)$ & \\
\hline \multicolumn{4}{|l|}{ Laterality (\%) } \\
\hline Right-sided primary & $36308(50.7)$ & $3888(47.4)$ & \multirow{3}{*}{$<0.001$} \\
\hline Left-sided primary & $35288(49.3)$ & $4276(52.1)$ & \\
\hline Bilateral & $51(0.1)$ & $46(0.6)$ & \\
\hline \multicolumn{4}{|l|}{ Histology (\%) } \\
\hline Clear Cell RCC & $41938(58.5)$ & $3771(45.7)$ & \multirow{5}{*}{$<0.001$} \\
\hline Papillary RCC & $9597(13.4)$ & $388(4.7)$ & \\
\hline Chromophobe RCC & $4320(6.0)$ & $70(0.8)$ & \\
\hline Sarcomatoid RCC & $555(0.8)$ & $490(5.9)$ & \\
\hline RCC, Unspecified & $15272(21.3)$ & $3525(42.8)$ & \\
\hline
\end{tabular}

(Continued) 


\begin{tabular}{lccc}
\hline & cM0 & cM1 & p-value \\
\hline cT stage (\%) & & & \\
cT1 & $51748(72.2)$ & $1886(22.9)$ & \\
cT2 & $7938(11.1)$ & $1612(19.6)$ & $<0.001$ \\
cT3 & $11437(16.0)$ & $3522(42.7)$ & \\
cT4 & $559(0.8)$ & $1224(14.8)$ & $<0.001$ \\
cN stage (\%), & & & \\
CN1 & $1345(1.9)$ & $2795(33.9)$ & $<0.001$ \\
Fuhrman Grade (\%) & & $70(3.3)$ & \\
$\quad$ Grade 1 & $3559(11.2)$ & $485(23.2)$ & \\
Grade 2 & $17405(54.5)$ & $833(39.9)$ & \\
Grade 3 & $9162(28.7)$ & $702(33.6)$ & \\
Grade 4 & $1788(5.6)$ & $4441(54.1)$ & $<0.001$ \\
Surgical Intervention (\%) & & $164(2.0)$ & $<0.001$ \\
$\quad$ No Surgery & $6293(8.8)$ & $3598(43.9)$ & \\
Partial Nephrectomy & $22733(31.8)$ & $3871(47.0)$ & \\
Radical Nephrectomy/ & &
\end{tabular}

\section{Utilization of Targeted Therapy over Time, Stratified by cM status}

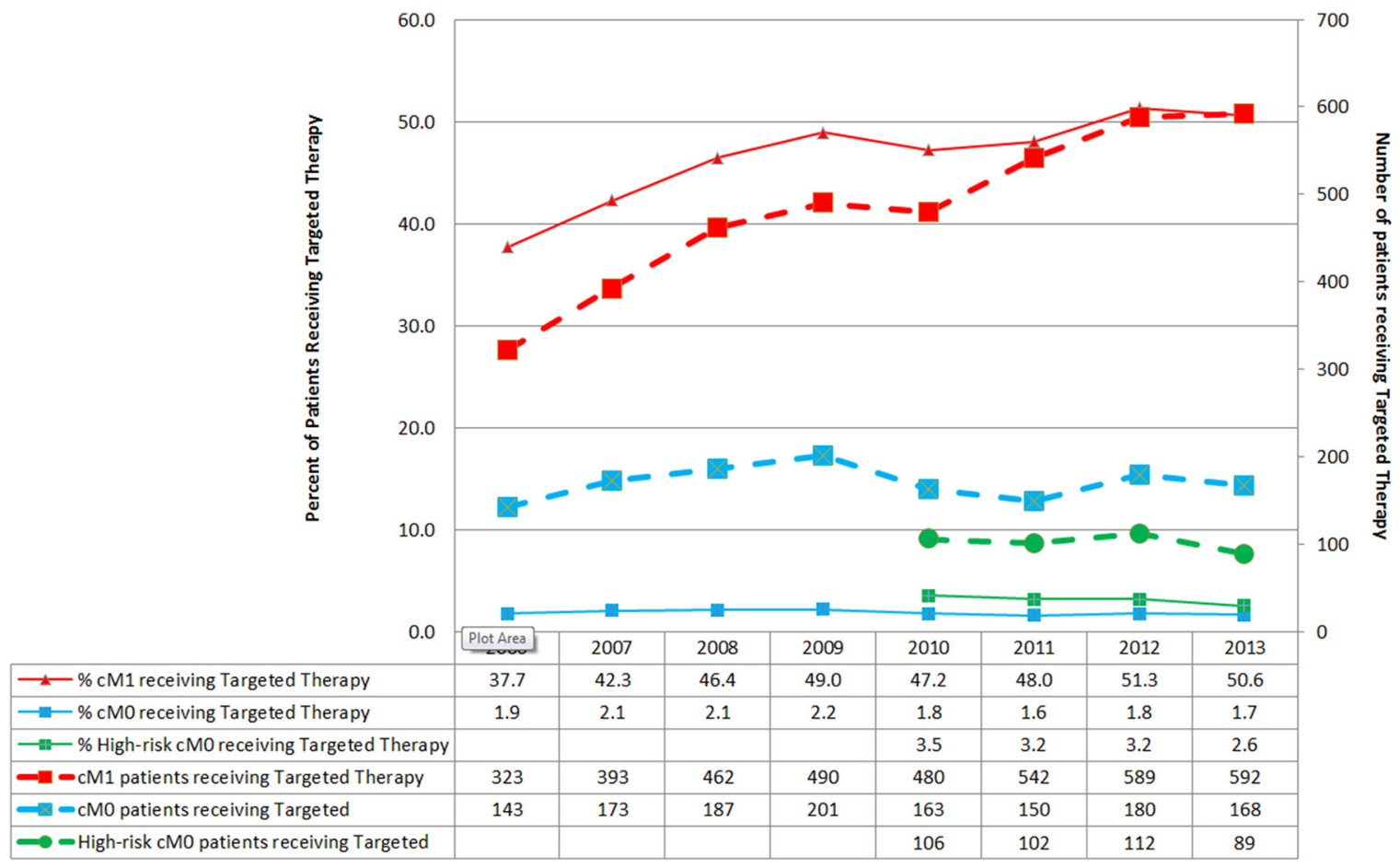

Figure 1: Utilization of targeted therapy over time, stratified by cM status. 
Table 2A: Predictors of targeted therapy receipt in cM1 patients, multivariable logistic regression analysis

\begin{tabular}{|c|c|c|c|c|}
\hline & \multirow{2}{*}{ OR } & \multicolumn{2}{|c|}{ 95\% CI for $O R$} & \multirow{2}{*}{$p$-Value } \\
\hline & & Lower & Higher & \\
\hline Age at Diagnosis & 0.97 & 0.96 & 0.97 & $<0.01$ \\
\hline \multicolumn{5}{|l|}{$\operatorname{Sex}$} \\
\hline Male & \multicolumn{4}{|c|}{ Reference } \\
\hline Female & 0.95 & 0.85 & 1.06 & 0.37 \\
\hline \multicolumn{5}{|l|}{ Race } \\
\hline Non-Hispanic White & \multicolumn{4}{|c|}{ Reference } \\
\hline Hispanic & 1 & 0.86 & 1.17 & 0.99 \\
\hline Native American & 2.18 & 1.31 & 3.62 & $<0.01$ \\
\hline Asian or Pacific Islander & 1.2 & 0.96 & 1.5 & 0.11 \\
\hline Non-Hispanic Black & 0.81 & 0.68 & 0.97 & 0.02 \\
\hline \multicolumn{5}{|l|}{ Socioeconomic Status } \\
\hline First Quartile (highest) & \multicolumn{4}{|c|}{ Reference } \\
\hline Second Quartile & 0.85 & 0.72 & 1 & 0.04 \\
\hline Third Quartile & 0.84 & 0.72 & 0.98 & 0.03 \\
\hline Fourth Quartile (lowest) & 0.78 & 0.66 & 0.91 & $<0.01$ \\
\hline \multicolumn{5}{|l|}{ Insurance } \\
\hline Insured & \multicolumn{4}{|c|}{ Reference } \\
\hline Medicaid & 0.79 & 0.68 & 0.92 & $<0.01$ \\
\hline Uninsured & 0.69 & 0.54 & 0.88 & $<0.01$ \\
\hline \multicolumn{5}{|l|}{ Region } \\
\hline Northeast & \multicolumn{4}{|c|}{ Reference } \\
\hline Southeast & 1.08 & 0.89 & 1.3 & 0.43 \\
\hline Midwest & 1.18 & 0.98 & 1.42 & 0.07 \\
\hline West & 0.98 & 0.83 & 1.16 & 0.84 \\
\hline \multicolumn{5}{|l|}{ Marital Status } \\
\hline Married & \multicolumn{4}{|c|}{ Reference } \\
\hline Single & 0.63 & 0.55 & 0.73 & $<0.01$ \\
\hline Divorced/Separated & 0.97 & 0.83 & 1.13 & 0.66 \\
\hline Widowed & 0.71 & 0.59 & 0.84 & $<0.01$ \\
\hline \multicolumn{5}{|l|}{ Laterality } \\
\hline Bilateral primary & \multicolumn{4}{|c|}{ Reference } \\
\hline Left-sided primary & 1.11 & 0.55 & 2.25 & 0.77 \\
\hline Right-sided primary & 1.12 & 0.55 & 2.27 & 0.75 \\
\hline \multicolumn{5}{|l|}{ cT stage } \\
\hline$c T 1$ & \multicolumn{4}{|c|}{ Reference } \\
\hline$c T 2$ & 1.28 & 1.1 & 1.49 & $<0.01$ \\
\hline$c 73$ & 1.28 & 1.12 & 1.47 & $<0.01$ \\
\hline$c T 4$ & 1.4 & 1.18 & 1.66 & $<0.01$ \\
\hline
\end{tabular}




\begin{tabular}{|c|c|c|c|c|}
\hline & \multirow{2}{*}{$O R$} & \multicolumn{2}{|c|}{$95 \%$ CI for OR } & \multirow{2}{*}{ p-Value } \\
\hline & & Lower & Higher & \\
\hline \multicolumn{5}{|l|}{ cN stage } \\
\hline$c N O$ & \multicolumn{4}{|c|}{ Reference } \\
\hline$c N 1$ & 1.46 & 1.31 & 1.62 & $<0.01$ \\
\hline \multicolumn{5}{|l|}{ Histology } \\
\hline Clear cell $R C C$ & \multicolumn{4}{|c|}{ Reference } \\
\hline Papillary RCC & 0.88 & 0.69 & 1.12 & 0.31 \\
\hline Chromophobe RCC & 0.76 & 0.45 & 1.3 & 0.32 \\
\hline Sarcomatoid RCC & 0.93 & 0.75 & 1.15 & 0.48 \\
\hline \multicolumn{5}{|l|}{ Surgical Intervention } \\
\hline No Surgery & \multicolumn{4}{|c|}{ Reference } \\
\hline Partial Nephrectomy & 0.4 & 0.28 & 0.59 & $<0.01$ \\
\hline Radical Nephrectomy & 0.73 & 0.65 & 0.83 & $<0.01$ \\
\hline
\end{tabular}

CSS and 82\% 5-year OS. In treated patients in the entire cM0 cohort, 5-year CSS and OS were $45 \%$ and $41 \%$, respectively. In the high-risk cM0 cohort over a 4-year period, untreated patients had $89 \%$ CSS and $82 \%$ OS, while treated patients had 55\% CSS and 51\% OS.

\section{DISCUSSION}

The introduction of TTs has drastically changed the RCC treatment paradigm, specifically for metastatic disease. With improvements in progression-free survival in the range of 3-8 months, $[6,7,16]$ they have become a cornerstone of therapy for metastatic RCC $[1,2,17,18]$. However, with that success, there has been a significant effort to utilize these therapies in the adjuvant setting for high-risk localized or locally advanced RCC. Two randomized controlled trials provided conflicting evidence for its utility, $[12,15]$ and consensus is still pending regarding the appropriateness in this setting. While other groups have assessed survival outcomes in the cytokine era, [19-21] we utilized the SEER database to evaluate trends of TT utilization, particularly in the non-metastatic setting, thereby adding some context for the discussion regarding the benefit of adjuvant therapy.

For contrast, de novo metastatic RCC patients were evaluated first. The use of TTs for these patients has steadily increased since 2006, though they remain underutilized [17, 18, 21-24]. Their use provided cancerspecific survival benefit in the entire cM1 cohort and in the clear-cell subset (Supplementary Table 2B and 2C), and the primary benefit appears to be within the first 20 months (Figure 2A). While not unsurprising on its own, this data serves as an important comparison when assessing the use and efficacy of TTs in the non-metastatic setting.

Of note, while the benefit of cytoreductive nephrectomy was established in the cytokine era, [9] many retrospective studies have attempted to address the role of cytoreductive nephrectomy in the TT era $[8$, $11,25]$. In this study, in patients with cM1 disease who received TT, cytoreductive surgery significantly reduced CSM, suggesting continued benefit. However, without data regarding timing of TT in relation to surgery and patient-specific comorbidities, it is difficult to determine the specific benefit of cytoreductive surgery in the TT era.

In the cM0 patients, although the SEER database does not provide information regarding timing of TT in relation to surgery, due to lack of FDA approval, it is presumed that the primary utilization of TT was as salvage therapy for metastatic disease. Utilization trends are consistent with this, as utilization ranged between 1.6-2.2\% during this 8-year time period. Even amongst high-risk cM0 patients, classified based on ASSURE and S-TRAC criteria, utilization was limited (2.6-3.5\%). TT receipt was associated with an increased CSM in the entire cM0 cohort, high-risk cM0 cohort and the highrisk clear cell cM0 cohort (HR 1.65-1.84) (Table 4A and Supplementary Table 4C). While likely due to selection bias for patients with worse pathology and progression to metastatic disease, it highlights the fact that patients receiving targeted therapy have poor prognosis due to their disease. However, KM curves for these cohorts (Figure 2B and $2 \mathrm{C}$ ) highlight a few significant trends. First, the large proportions of $\mathrm{cM} 0$ patients that never received or required TT were more likely to die of other causes than RCC. Competing risks for other-cause mortality can significantly 


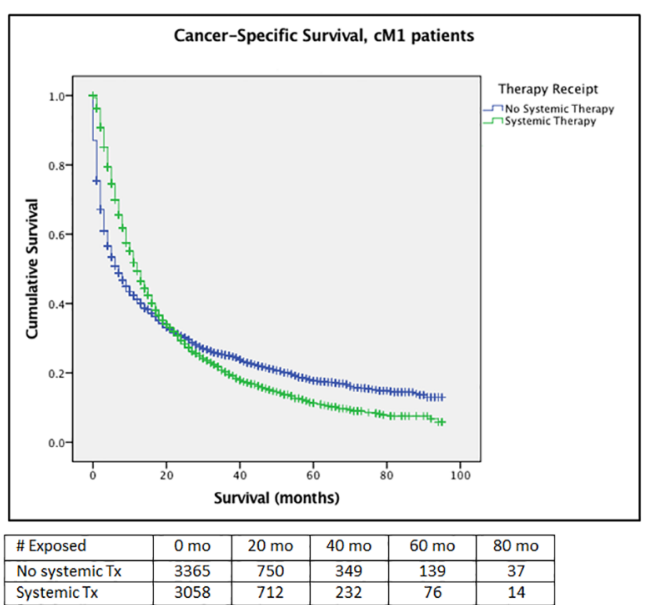

Log-rank $p<0.01$

B

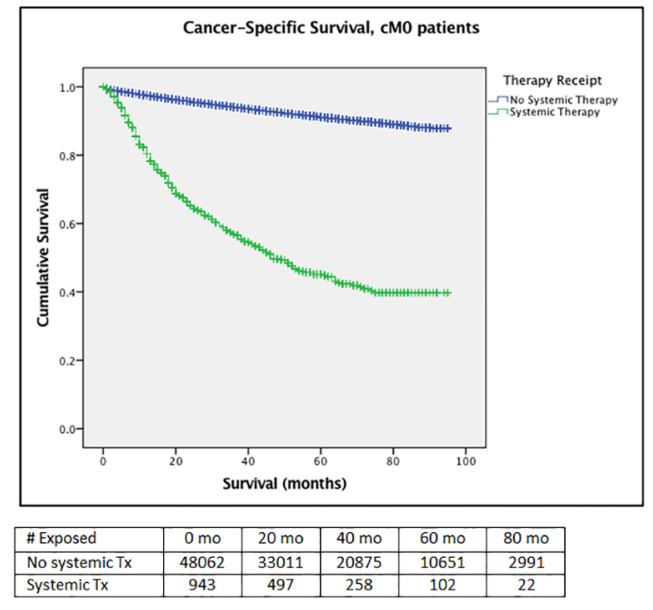

Log-rank $p<0.01$

C

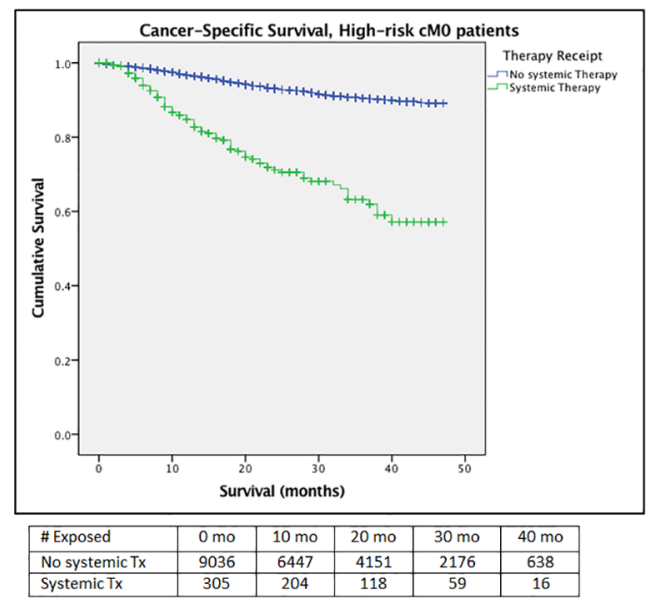

Log-rank $p<0.01$

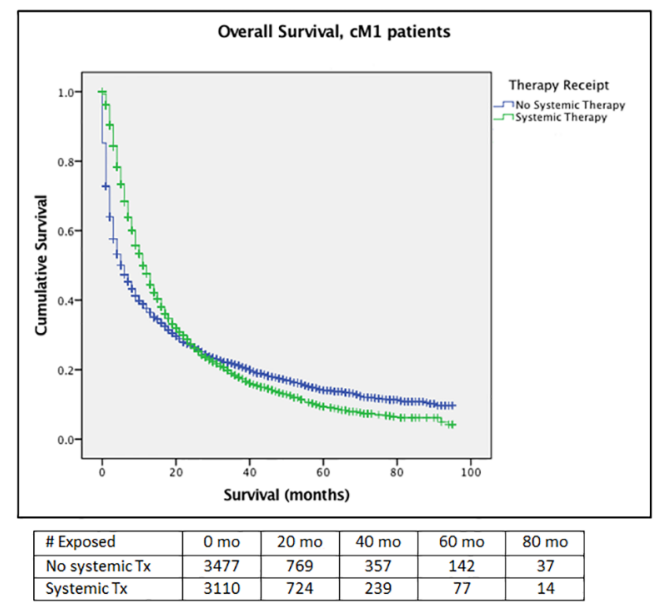

Log-rank $p<0.01$

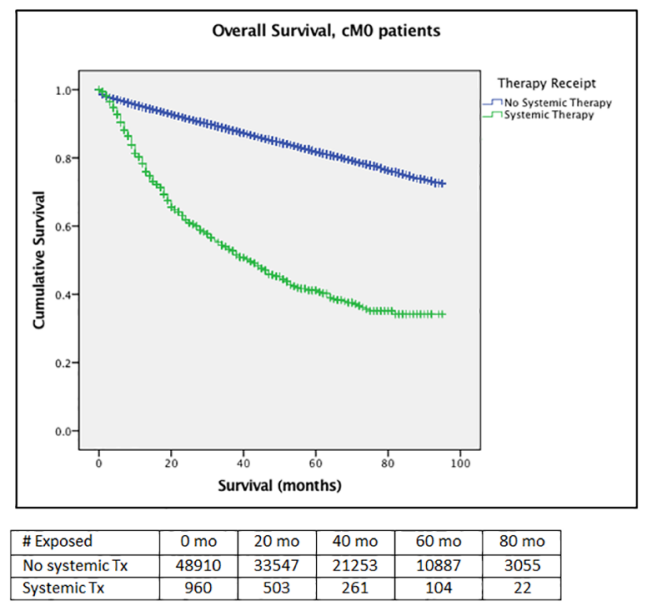

Log-rank $p<0.01$

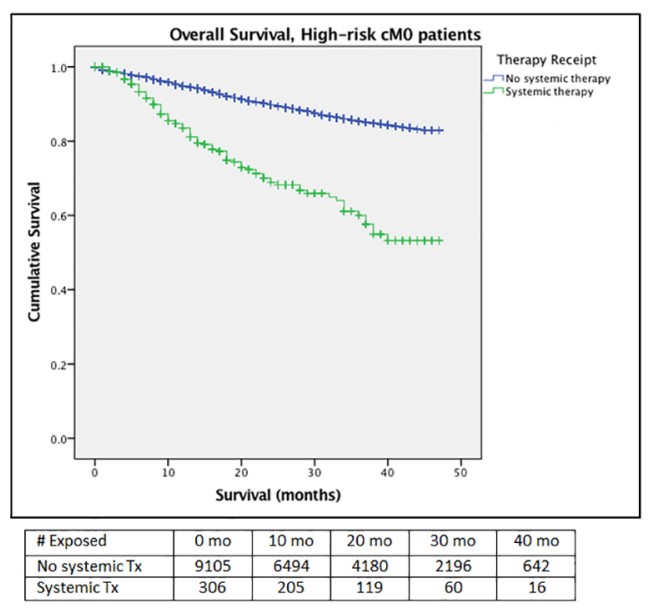

Log-rank $p<0.01$

Figure 2: Kaplan-Meier survival analyses. (A) Cancer-specific Survival and Overall Survival, cM1 patients (Entire cohort). (B) Cancer-specific Survival and Overall Survival, cM0 patients (Entire cohort). (C) Cancer-specific Survival and Overall Survival, High-risk cM0 patients. 
Table 3A: Predictors of targeted therapy receipt in cM0 patients, multivariable logistic regression analysis

\begin{tabular}{|c|c|c|c|c|}
\hline & \multirow{2}{*}{ OR } & \multicolumn{2}{|c|}{ 95\% CI for $O R$} & \multirow{2}{*}{ p Value } \\
\hline & & Lower & Higher & \\
\hline Age at Diagnosis & 0.97 & 0.97 & 0.98 & $<0.01$ \\
\hline \multicolumn{5}{|l|}{$\operatorname{Sex}$} \\
\hline Male & \multicolumn{4}{|c|}{ Reference } \\
\hline Female & 0.89 & 0.78 & 1.03 & 0.11 \\
\hline \multicolumn{5}{|l|}{ Race } \\
\hline Non-Hispanic White & \multicolumn{4}{|c|}{ Reference } \\
\hline Hispanic & 0.81 & 0.65 & 0.99 & 0.04 \\
\hline Native American & 0.58 & 0.26 & 1.31 & 0.19 \\
\hline Asian or Pacific Islander & 1.2 & 0.92 & 1.57 & 0.18 \\
\hline Non-Hispanic Black & 0.79 & 0.63 & 1 & 0.05 \\
\hline \multicolumn{5}{|l|}{ Socioeconomic Status } \\
\hline First Quartile (highest) & \multicolumn{4}{|c|}{ Reference } \\
\hline Second Quartile & 0.85 & 0.7 & 1.04 & 0.11 \\
\hline Third Quartile & 0.91 & 0.75 & 1.09 & 0.3 \\
\hline Fourth Quartile (lowest) & 0.73 & 0.6 & 0.89 & $<0.01$ \\
\hline \multicolumn{5}{|l|}{ Insurance } \\
\hline Insured & \multicolumn{4}{|c|}{ Reference } \\
\hline Medicaid & 0.86 & 0.69 & 1.07 & 0.18 \\
\hline Uninsured & 0.71 & 0.49 & 1.03 & 0.07 \\
\hline \multicolumn{5}{|l|}{ Region } \\
\hline Northeast & \multicolumn{4}{|c|}{ Reference } \\
\hline Southeast & 1.04 & 0.83 & 1.31 & 0.71 \\
\hline Midwest & 0.8 & 0.64 & 1.01 & 0.06 \\
\hline West & 0.96 & 0.79 & 1.17 & 0.68 \\
\hline \multicolumn{5}{|l|}{ Marital Status } \\
\hline Married & \multicolumn{4}{|c|}{ Reference } \\
\hline Single & 0.76 & 0.63 & 0.92 & 0.01 \\
\hline Divorced/Separated & 0.87 & 0.7 & 1.07 & 0.19 \\
\hline Widowed & 0.76 & 0.59 & 0.98 & 0.03 \\
\hline \multicolumn{5}{|l|}{ Laterality } \\
\hline Bilateral primary & \multicolumn{4}{|c|}{ Reference } \\
\hline Left-sided primary & 1.01 & 0.25 & 4.08 & 0.99 \\
\hline Right-sided primary & 0.9 & 0.22 & 3.63 & 0.88 \\
\hline \multicolumn{5}{|l|}{ cT stage } \\
\hline$c T 1$ & \multicolumn{4}{|c|}{ Reference } \\
\hline$c T 2$ & 3.91 & 3.2 & 4.78 & $<0.01$ \\
\hline cT3 & 9.16 & 7.75 & 10.84 & $<0.01$ \\
\hline$c T 4$ & 18.67 & 14 & 24.91 & $<0.01$ \\
\hline
\end{tabular}




\begin{tabular}{|c|c|c|c|c|}
\hline & \multirow{2}{*}{ OR } & \multicolumn{2}{|c|}{ 95\% CI for $O R$} & \multirow{2}{*}{ p Value } \\
\hline & & Lower & Higher & \\
\hline \multicolumn{5}{|l|}{ cN stage } \\
\hline cNO & \multicolumn{4}{|c|}{ Reference } \\
\hline$c N 1$ & 5.7 & 4.79 & 6.78 & $<0.01$ \\
\hline \multicolumn{5}{|l|}{ Histology } \\
\hline Clear cell RCC & \multicolumn{4}{|c|}{ Reference } \\
\hline Papillary RCC & 0.99 & 0.8 & 1.23 & 0.93 \\
\hline Chromophobe RCC & 0.56 & 0.39 & 0.79 & $<0.01$ \\
\hline Sarcomatoid RCC & 2.7 & 2 & 3.64 & $<0.01$ \\
\hline \multicolumn{5}{|l|}{ Surgical Intervention } \\
\hline No Surgery & \multicolumn{4}{|c|}{ Reference } \\
\hline Partial Nephrectomy & 0.05 & 0.04 & 0.07 & $<0.01$ \\
\hline Radical Nephrectomy & 0.15 & 0.13 & 0.19 & $<0.01$ \\
\hline
\end{tabular}

limit the utility of TT in a large unselected population. Additionally, the small population of patients treated with TT in these cohorts fared much better than patients with cM1 disease at diagnosis.

This large dataset provides some key contributions to the discussion of adjuvant therapy for RCC. Five-year disease progression (recurrence, second malignancy, death) in the placebo arms of ASSURE and S-TRAC were $36.8 \%$ and $48.7 \%$, respectively. However, the strict selection bias for clinical trials limits their generalizability $[12,15]$. In our cohort, $2-3 \%$ of the cM0 population received TT. As such, providing adjuvant therapy for the entire population or even the entire high-risk cM0 population could result in overtreatment in $97-98 \%$ of patients. Even accounting for underutilization, recurrence rates for cM0 patients managed surgically have been reported to be $10-20 \%$ [26]. As these targeted therapies are known to have significant adverse events, [27] this would subject a large population to unnecessary significant toxicity.

From a survival benefit standpoint, the large proportion of patients $\mathrm{cM} 0$ patients who never progress to needing salvage therapy are likely to die of non-RCC related causes rather than RCC itself. The small proportion that do progress to metastatic disease and are initiated on targeted therapy still have better CSS and OS than patients diagnosed with de novo metastatic disease, suggesting that salvage therapy is still a viable option with survival benefit.

Our study has clear limitations, including the lack of granularity in the SEER database as it relates to the TT agents, therapy sequencing and timing, patient comorbidities, and timing of clinical progression. This precludes our ability to analyze the subset of $\mathrm{cM} 0$ patients who did progress to metastatic disease, which could enable better selection of patients that may benefit from adjuvant therapy. Additionally, we are unable to identify the specific TT utilized, and traditional chemotherapeutic agents may potentially be included in the TT analysis; however, as RCC has been known to be chemo-resistant, the incidence is likely to be low during the TT era. Prior studies have demonstrated very low rates of chemotherapy use prior to the introduction of targeted therapies [17, 18, 21]. Lastly, as it relates to the chemotherapy variable, prior comparison to SEER-Medicare datasets have demonstrated $65-80 \%$ sensitivity, but very high specificity [28]. As such, the SEER registries specifically list utilization as "Yes" or "No/Unknown," which we adhere to in the included analyses. It is possible, therefore, that utilization rates in our study underestimate true utilization by $25-50 \%$. However, with utilization rates as low as they are, this would increase utilization to approximately $5 \%$ even in the high-risk cohort.

Despite its limitations, this study is the largest population-based study to assess the use of TT in the management of RCC. By evaluating its utilization and survival impact in both the de novo metastatic and cM0 setting, we demonstrate the potential effect of using TTs as adjuvant therapy in a more generalizable setting. Specifically, unlike the prior RCTs, we highlight the potential over-treatment of cM0 patients who are unlikely to ever need TT and the survival benefit afforded by salvage therapy. In an unscreened and unselected population, competing risks for othercause mortality may limit the utility of adjuvant therapy in cM0 RCC. Our results reinforce the findings of the ASSURE trial, $[12,14]$ and thereby provides population-based support for not using TT in an adjuvant setting. 
Table 4A: Predictors of cancer-specific mortality in cM0 patients, fine and gray competing risk proportional hazards regressions analysis

\begin{tabular}{|c|c|c|c|c|}
\hline & \multirow{2}{*}{$H R$} & \multicolumn{2}{|c|}{ 95\% CI for $H R$} & \multirow{2}{*}{ p Value } \\
\hline & & Lower & Higher & \\
\hline Age at Diagnosis & 1.03 & 1.03 & 1.04 & $<0.01$ \\
\hline \multicolumn{5}{|l|}{$\operatorname{Sex}$} \\
\hline Female & \multicolumn{4}{|c|}{ Reference } \\
\hline Male & 1.1 & 1.02 & 1.19 & 0.01 \\
\hline \multicolumn{5}{|l|}{ Race } \\
\hline Non-Hispanic White & \multicolumn{4}{|c|}{ Reference } \\
\hline Hispanic & 1 & 0.9 & 1.1 & 0.92 \\
\hline Native American & 1.01 & 0.71 & 1.43 & 0.97 \\
\hline Asian or Pacific Islander & 1.07 & 0.92 & 1.25 & 0.36 \\
\hline Non-Hispanic Black & 1.08 & 0.96 & 1.22 & 0.22 \\
\hline \multicolumn{5}{|l|}{ Socioeconomic Status } \\
\hline First Quartile (highest) & \multicolumn{4}{|c|}{ Reference } \\
\hline Second Quartile & 0.96 & 0.86 & 1.07 & 0.47 \\
\hline Third Quartile & 1.1 & 0.98 & 1.23 & 0.1 \\
\hline Fourth Quartile (lowest) & 1.08 & 0.97 & 1.2 & 0.16 \\
\hline \multicolumn{5}{|l|}{ Insurance } \\
\hline Insurance & \multicolumn{4}{|c|}{ Reference } \\
\hline Medicaid & 1.2 & 1.05 & 1.37 & 0.01 \\
\hline Uninsured & 1.25 & 1.02 & 1.53 & 0.03 \\
\hline \multicolumn{5}{|l|}{ Region } \\
\hline Northeast & \multicolumn{4}{|c|}{ Reference } \\
\hline Southeast & 1.18 & 1.04 & 1.33 & 0.01 \\
\hline Midwest & 1.03 & 0.91 & 1.18 & 0.61 \\
\hline West & 1.02 & 0.92 & 1.14 & 0.67 \\
\hline \multicolumn{5}{|l|}{ Marital Status } \\
\hline Married & \multicolumn{4}{|c|}{ Reference } \\
\hline Single & 1.12 & 0.97 & 1.27 & 0.08 \\
\hline Divorced/Separated & 1.19 & 1.07 & 1.32 & $<0.01$ \\
\hline Widowed & 1.22 & 1.1 & 1.37 & $<0.01$ \\
\hline \multicolumn{5}{|l|}{ Laterality } \\
\hline Right-sided primary & \multicolumn{4}{|c|}{ Reference } \\
\hline Left-sided primary & 1 & 0.93 & 1.07 & 0.99 \\
\hline Bilateral primary & 1.88 & 0.9 & 3.9 & 0.09 \\
\hline \multicolumn{5}{|l|}{ cT stage } \\
\hline$c T 1$ & \multicolumn{4}{|c|}{ Reference } \\
\hline$c T 2$ & 2.77 & 2.52 & 3.05 & $<0.01$ \\
\hline$c T 3$ & 4.51 & 4.15 & 4.89 & $<0.01$ \\
\hline$c T 4$ & 8.26 & 6.53 & 10.46 & $<0.01$ \\
\hline & & & & (Continued) \\
\hline
\end{tabular}




\begin{tabular}{|c|c|c|c|c|}
\hline & \multirow{2}{*}{$H R$} & \multicolumn{2}{|c|}{ 95\% CI for $H R$} & \multirow{2}{*}{ p Value } \\
\hline & & Lower & Higher & \\
\hline \multicolumn{5}{|l|}{ cN stage } \\
\hline$c N O$ & \multicolumn{4}{|c|}{ Reference } \\
\hline$c N 1$ & 3.64 & 3.18 & 4.16 & $<0.01$ \\
\hline \multicolumn{5}{|l|}{ Histology } \\
\hline Clear cell RCC & \multicolumn{4}{|c|}{ Reference } \\
\hline Papillary $R C C$ & 1 & 0.88 & 1.13 & 0.97 \\
\hline Chromophobe RCC & 0.47 & 0.38 & 0.58 & $<0.01$ \\
\hline Sarcomatoid RCC & 4.13 & 3.4 & 5.03 & $<0.01$ \\
\hline \multicolumn{5}{|l|}{ Surgical Intervention } \\
\hline No surgery & \multicolumn{4}{|c|}{ Reference } \\
\hline Partial Nephrectomy & 0.13 & 0.11 & 0.15 & $<0.01$ \\
\hline Radical Nephrectomy & 0.33 & 0.29 & 0.37 & $<0.01$ \\
\hline \multicolumn{5}{|c|}{ Receipt of Targeted Therapy } \\
\hline No/Unknown & \multicolumn{4}{|c|}{ Reference } \\
\hline Yes & 1.84 & 1.58 & 2.14 & $<0.01$ \\
\hline
\end{tabular}

\section{MATERIALS AND METHODS}

\section{Study population}

The Surveillance, Epidemiology, and End Results (SEER) database reports cancer-specific outcomes from specific geographic areas representing $28 \%$ of the US population. Using the SEER database, we identified patients with five RCC-specific histology codes and the kidney as primary tumor site. Patients receiving radiotherapy prior to therapy were excluded $(\mathrm{N}=335)$. Only patients diagnosed after 2006 were included to capture the targeted therapy era $[3,5]$.

\section{Description of covariates}

Demographic variables of interest included age at diagnosis, gender, race, insurance status, marital status, and region based on SEER registry (West, Northeast, Southeast, Midwest). Based on prior literature, [29] a county-level socioeconomic (SES) measure was created, based on the percentage of individuals (i) with less than a high school education, (ii) below the poverty line, (iii) unemployed, (iv) foreign-born, and (v) median household income. Disease-specific covariates included clinical stage (T-stage [cT], N-stage [cN], and M-stage [cM]), primary histology type, histologic grade (2010-2013 only), surgical intervention (radical nephrectomy or partial nephrectomy), and receipt of targeted therapy.
While TTs, including sunitinib, sorafenib, temsirolimus, everolimus, pazopanib, axitinib, and cabozantinib, are captured by the SEER chemotherapy variable, immunotherapies (bevacizumab, IL-2, immune checkpoint inhibitors) are not.

\section{Statistical analysis}

Patients were stratified by cM status (cM0 vs cM1), and $\mathrm{cM} 0$ patients who underwent primary surgery were subsequently risk stratified. As Furhman Grade (FG), an important component of the "high-risk" designation for localized RCC, is only available from 2010-2013, only these patients were included in this subset analysis. Based on a combination of the ASSURE and S-TRAC clinical trials, $[12,15]$ the following patients were considered high-risk cM0 RCC: cT1-2 \& FG 3-4, cT3 \& FG 2-4, any cT4 disease, and $\mathrm{cN} 1$ disease. All other cM0 patients who underwent primary surgery in the 2010-2013 cohort were classified as low-risk cM0.

Descriptive statistics for demographic and socioeconomic variable comparisons were performed by the Student t-test for continuous variables and the chisquare test for categorical variables. Multivariable logistic regression models were performed to generate odds ratios (ORs) for the identification of factors associated with receipt of targeted therapy. Fine and Gray competing risks proportional regression modeling, censoring for non-cancer mortality, was performed to generate hazards 
ratios (HR) to identify predictors of cancer-specific mortality (CSM). Given the sample size and appropriate number of events, our variable selection was exploratory in nature, including all variables in the regression models. A subset analysis of clear cell RCC histology patients and high-risk cM0 patients was also performed. KaplanMeier analysis (log-rank test) was used to evaluate overall survival (OS) and cancer-specific survival (CSS) for the same cohorts, stratified based on receipt of targeted therapy. All statistical tests were two-tailed and a p-value $<0.05$ was considered statistically significant. Statistical tests were performed using R statistical package - R Core Team (2012) and SAS 9.4 (SAS Institute, Cary, North Carolina).

\section{Key message}

Population-level analyses highlight the low utilization of targeted therapy in cM0 patients and the potential overtreatment that could result from an adjuvant therapy paradigm in RCC. Competing risks for othercause mortality make the real-world utility of adjuvant targeted therapy limited.

\section{Author contributions}

TC: Conceptualization, Data Curation, Formal Analysis, Writing (Original, Review \& Editing).

ZK \& HG: Formal Analysis, Writing (Review \& Editing).

RJH, GSK, NEF: Resources \& Supervision.

\section{CONFLICTS OF INTEREST}

All authors report no conflicts of interest.

\section{REFERENCES}

1. Ljungberg $\mathrm{B}$, Bensalah $\mathrm{K}$, Canfield S, Dabestani S, Hofmann F, Hora M, Kuczyk MA, Lam T, Marconi L, Merseburger AS, Mulders P, Powles T, Staehler M, et al. EAU guidelines on renal cell carcinoma: 2014 update. Eur Urol. 2015; 67:913-24. https://doi.org/10.1016/j. eururo.2015.01.005.

2. Motzer RJ, Jonasch E, Agarwal N, Beard C, Bhayani S, Bolger GB, Chang SS, Choueiri TK, Costello BA, Derweesh IH, Gupta S, Hancock SL, Kim JJ, et al, and National comprehensive cancer network. Kidney cancer, version 3.2015. J Natl Compr Canc Netw. 2015; 13:151-59. https://doi.org/10.6004/jnccn.2015.0022.

3. Motzer RJ, Rini BI, Bukowski RM, Curti BD, George DJ, Hudes GR, Redman BG, Margolin KA, Merchan JR, Wilding G, Ginsberg MS, Bacik J, Kim ST, et al.
Sunitinib in patients with metastatic renal cell carcinoma. JAMA. 2006; 295:2516-24. https://doi.org/10.1001/ jama.295.21.2516.

4. Escudier B, Eisen T, Stadler WM, Szczylik C, Oudard S, Siebels M, Negrier S, Chevreau C, Solska E, Desai AA, Rolland F, Demkow T, Hutson TE, et al, and TARGET Study Group. Sorafenib in advanced clear-cell renal-cell carcinoma. N Engl J Med. 2007; 356:125-34. https://doi. org/10.1056/NEJMoa060655.

5. Motzer RJ, Hutson TE, Tomczak P, Michaelson MD, Bukowski RM, Rixe O, Oudard S, Negrier S, Szczylik C, Kim ST, Chen I, Bycott PW, Baum CM, Figlin RA. Sunitinib versus interferon alfa in metastatic renal-cell carcinoma. N Engl J Med. 2007; 356:115-24. https://doi. org/10.1056/NEJMoa065044.

6. Merza H, Bilusic M. Current Management Strategy for Metastatic Renal Cell Carcinoma and Future Directions. Curr Oncol Rep. 2017; 19:27. https://doi.org/10.1007/ s11912-017-0583-8.

7. Greef B, Eisen T. Medical treatment of renal cancer: new horizons. Br J Cancer. 2016; 115:505-16. https://doi. org/10.1038/bjc.2016.230.

8. de Groot S, Redekop WK, Sleijfer S, Oosterwijk E, Bex A, Kiemeney LA, Uyl-de Groot CA. Survival in Patients With Primary Metastatic Renal Cell Carcinoma Treated With Sunitinib With or Without Previous Cytoreductive Nephrectomy: Results From a Population-based Registry. Urology. 2016; 95:121-27. https://doi.org/10.1016/j. urology.2016.04.042.

9. Flanigan RC, Mickisch G, Sylvester R, Tangen C, Van Poppel H, Crawford ED. Cytoreductive nephrectomy in patients with metastatic renal cancer: a combined analysis. J Urol. 2004; 171:1071-76. https://doi.org/10.1097/01. ju.0000110610.61545.ae.

10. Biswas B, Dabkara D, Ganguly S, Eswaran P, Ghosh J. Cytoreductive Nephrectomy in Metastatic Renal Cell Carcinoma in the Era of Targeted Therapy: Scientifically Relevant or Natural Selection? J Clin Oncol. 2017; 35:1265-66. https://doi.org/10.1200/JCO.2016.70.8156.

11. Hanna N, Sun M, Meyer CP, Nguyen PL, Pal SK, Chang SL, de Velasco G, Trinh QD, Choueiri TK. Survival Analyses of Patients With Metastatic Renal Cancer Treated With Targeted Therapy With or Without Cytoreductive Nephrectomy: A National Cancer Data Base Study. J Clin Oncol. 2016; 34:3267-75. https://doi.org/10.1200/ JCO.2016.66.7931.

12. Haas NB, Manola J, Uzzo RG, Flaherty KT, Wood CG, Kane C, Jewett M, Dutcher JP, Atkins MB, Pins M, Wilding G, Cella D, Wagner L, et al. Adjuvant sunitinib or sorafenib for high-risk, non-metastatic renal-cell carcinoma (ECOGACRIN E2805): a double-blind, placebo-controlled, randomised, phase 3 trial. Lancet. 2016; 387:2008-16. https://doi.org/10.1016/S0140-6736(16)00559-6. 
13. Bex A, Albiges L, Ljungberg B, Bensalah K, Dabestani S, Giles RH, Hofmann F, Hora M, Kuczyk MA, Lam TB, Marconi L, Merseburger AS, Staehler M, et al, and Updated European Association of Urology Guidelines Regarding Adjuvant Therapy for Renal Cell Carcinoma. Updated European Association of Urology Guidelines Regarding Adjuvant Therapy for Renal Cell Carcinoma. Eur Urol. 2017; 71:719-22. https://doi.org/10.1016/j. eururo.2016.11.034.

14. Haas NB, Manola J, Dutcher JP, Flaherty KT, Uzzo RG, Atkins MB, DiPaola RS, Choueiri TK. Adjuvant Treatment for High-Risk Clear Cell Renal Cancer: Updated Results of a High-Risk Subset of the ASSURE Randomized Trial. JAMA Oncol. 2017; 3:1249-52. https://doi.org/10.1001/ jamaoncol.2017.0076.

15. Ravaud A, Motzer RJ, Pandha HS, George DJ, Pantuck AJ, Patel A, Chang YH, Escudier B, Donskov F, Magheli A, Carteni G, Laguerre B, Tomczak P, et al, and S-TRAC Investigators. Adjuvant Sunitinib in High-Risk RenalCell Carcinoma after Nephrectomy. N Engl J Med. 2016; 375:2246-54. https://doi.org/10.1056/NEJMoa1611406.

16. Vachhani P, George S. VEGF inhibitors in renal cell carcinoma. Clin Adv Hematol Oncol. 2016; 14:1016-28.

17. Pal SK, Signorovitch JE, Li N, Zichlin ML, Liu Z, Ghate SR, Perez JR, Vogelzang NJ. Patterns of care among patients receiving sequential targeted therapies for advanced renal cell carcinoma: A retrospective chart review in the USA. Int J Urol. 2017; 24:272-78. https://doi.org/10.1111/ iju.13314.

18. Psutka SP, Kim SP, Gross CP, Van Houten H, Thompson RH, Abouassaly R, Weight C, Boorjian SA, Leibovich BC, Shah ND. The impact of targeted therapy on management of metastatic renal cell carcinoma: trends in systemic therapy and cytoreductive nephrectomy utilization. Urology. 2015; 85:442-50. https://doi.org/10.1016/j.urology.2014.10.040.

19. Vaishampayan U, Vankayala H, Vigneau FD, Quarshie W, Dickow B, Chalasani S, Schwartz K. The effect of targeted therapy on overall survival in advanced renal cancer: a study of the national surveillance epidemiology and end results registry database. Clin Genitourin Cancer. 2014; 12:124-29. https://doi.org/10.1016/j.clgc.2013.09.007.

20. Shek D, Tomlinson B, Brown M, Brunson A, Pan CX, Lara PN Jr. Epidemiologic trends in renal cell carcinoma in the cytokine and post-cytokine eras: a registry analysis of
28,252 patients. Clin Genitourin Cancer. 2012; 10:93-98. https://doi.org/10.1016/j.clgc.2012.01.007.

21. Ferry EK, Minnillo BJ, Maurice MJ, Abouassaly R, Zhu H. Trends of Systemic Therapy Use for Renal Cell Carcinoma in the United States. Urology. 2015; 85:1399-403. https:// doi.org/10.1016/j.urology.2015.03.008.

22. Banegas MP, Harlan LC, Mann B, Yabroff KR. Renal cell cancer: a shift in approaches for treatment of advanced disease in the United States. J Natl Compr Canc Netw. 2014; 12:1271-79. https://doi.org/10.6004/jnccn.2014.0124.

23. Smaldone MC, Handorf E, Kim SP, Thompson RH, Costello BA, Corcoran AT, Wong YN, Uzzo RG, Leibovich BC, Kutikov A, Boorjian SA. Temporal trends and factors associated with systemic therapy after cytoreductive nephrectomy: an analysis of the National Cancer Database. J Urol. 2015; 193:1108-13. https://doi.org/10.1016/j. juro.2014.10.095.

24. De Groot S, Sleijfer S, Redekop WK, Oosterwijk E, Haanen JB, Kiemeney LA, Uyl-de Groot CA. Variation in use of targeted therapies for metastatic renal cell carcinoma: results from a Dutch population-based registry. BMC Cancer. 2016; 16:364. https://doi.org/10.1186/s12885-016-2395-x.

25. Abern MR, Scosyrev E, Tsivian M, Messing EM, Polascik TJ, Dudek AZ. Survival of patients undergoing cytoreductive surgery for metastatic renal cell carcinoma in the targeted-therapy era. Anticancer Res. 2014; 34:2405-11.

26. Azawi NH, Tesfalem H, Mosholt KS, Høyerup P, Jensen ES, Malchau E, Fode M. Recurrence rates and survival in a Danish cohort with renal cell carcinoma. Dan Med J. 2016; 63:63.

27. Pham A, Ye DW, Pal S. Overview and management of toxicities associated with systemic therapies for advanced renal cell carcinoma. Urol Oncol. 2015; 33:517-27. https:// doi.org/10.1016/j.urolonc.2015.07.020.

28. Noone AM, Lund JL, Mariotto A, Cronin K, McNeel T, Deapen D, Warren JL. Comparison of SEER Treatment Data With Medicare Claims. Med Care. 2016; 54:e55-64. https://doi.org/10.1097/MLR.0000000000000073.

29. Chandrasekar T, Klaassen Z, Goldberg H, Kulkarni GS, Hamilton RJ, Fleshner NE. Metastatic renal cell carcinoma: patterns and predictors of metastases-A contemporary population-based series. Urol Oncol. 2017; 35:661.e7-14. https://doi.org/10.1016/j.urolonc.2017.06.060. 